\title{
Association of parity with birthweight and neonatal death in five sites: The Global Network's Maternal Newborn Health Registry study
}

\author{
Ana Garces ${ }^{1 *}$, Wilton Perez ${ }^{1}$, Margo S. Harrison², Kay S. Hwang ${ }^{3}$, Tracy L. Nolen ${ }^{3}$, Robert L. Goldenberg4, \\ Archana B. Patel ${ }^{5}$, Patricia L. Hibberd ${ }^{6}$, Adrien Lokangaka ${ }^{7}$, Antoinette Tshefu ${ }^{7}$, Sarah Saleem ${ }^{8}$, \\ Shivaprasad S. Goudar ${ }^{9}$, Richard J. Derman ${ }^{10}$, Jacquelyn Patterson ${ }^{11}$, Marion Koso-Thomas ${ }^{12}$, \\ Elizabeth M. McClure ${ }^{3}$, Nancy F. Krebs ${ }^{2}$ and K. Michael Hambidge ${ }^{2}$
}

\begin{abstract}
Background: Nulliparity has been associated with lower birth weight (BW) and other adverse pregnancy outcomes, with most of the data coming from high-income countries. In this study, we examined birth weight for gestational age z-scores and neonatal (28-day) mortality in a large prospective cohort of women dated by first trimester ultrasound from multiple sites in low and middle-income countries.

Methods: Pregnant women were recruited during the first trimester of pregnancy and followed through 6 weeks postpartum from Maternal Newborn Health Registry (MNHR) sites in the Democratic Republic of Congo (DRC), Guatemala, Belagavi and Nagpur, India, and Pakistan from 2017 and 2018. Data related to the pregnancy and its outcomes were collected prospectively. First trimester ultrasound was used for determination of gestational age; (BW) was obtained in grams within $48 \mathrm{~h}$ of delivery and later transformed to weight for age $\mathrm{z}$-scores (WAZ) adjusted for gestational age using the INTERGROWTH-21st standards.

Results: 15,121 women were eligible and included. Infants of nulliparous women had lower mean BWs (males: $2676 \mathrm{gr}$, females: $2587 \mathrm{gr}$, total: $2634 \mathrm{gr}$ ) and gestational age adjusted weight for age z-scores (males: - 0.73, females: -0.77 , total: -0.75 ,) than women with one or more previous pregnancies. The largest differences were between zero and one previous pregnancies among female infants. The associations of parity with BW and z-scores remained even after adjustment for maternal age, maternal height, maternal education, antenatal care visits, hypertensive disorders, and socioeconomic status. Nulliparous women also had a significantly higher $<28$-day neonatal mortality rate (27.7 per 1,000 live births) than parous women (17.2 and 20.7 for parity of $1-3$ and $\geq 4$ respectively). Risk of preterm birth was higher among women with $\geq 4$ previous pregnancies (15.5\%) compared to $11.3 \%$ for the nulliparous group and $11.8 \%$ for women with one to three previous pregnancies $(p=0.0072)$.
\end{abstract}

Conclusions: In this large sample from diverse settings, nulliparity was independently associated with both lower BW and WAZ scores as well as higher neonatal mortality compared to multiparity.

*Correspondence: anagarcesdelvalle@gmail.com

${ }^{1}$ Instituto de Nutrición de Centroamérica y Panamá, Guatemala City, Guatemala

Full list of author information is available at the end of the article

c) The Author(s) 2020. This article is licensed under a Creative Commons Attribution 4.0 International License, which permits use, sharing, adaptation, distribution and reproduction in any medium or format, as long as you give appropriate credit to the original author(s) and the source, provide a link to the Creative Commons licence, and indicate if changes were made. The images or other third party material in this article are included in the article's Creative Commons licence, unless indicated otherwise in a credit line to the material. If material is not included in the article's Creative Commons licence and your intended use is not permitted by statutory regulation or exceeds the permitted use, you will need to obtain permission directly from the copyright holder. To view a copy of this licence, visit http://creativecommons.org/licenses/by/4.0/. The Creative Commons Public Domain Dedication waiver (http://creativecommons.org/publicdomain/zero/1.0/) applies to the data made available in this article, unless otherwise stated in a credit line to the data. 
Keywords: Nulliparity, Birth weight, Neonatal death, Pregnancy outcomes, Global network

\section{Background}

The Maternal Newborn Health Registry (MNHR) is a prospective, population-based registry of pregnancies and deliveries conducted under the auspices of the Global Network for Women's and Children's Health Research (GN), a multi-country research network funded by the Eunice Kennedy Shriver National Institute of Child Health and Human Development (NICHD) [1, 2]. The primary purpose of the MNHR is to quantify and analyze trends in pregnancy outcomes over time [3, 4].

Neonates born to nulliparous women are reported to be at higher risk of death and other adverse outcomes, including low BW, being small for gestational age, and prematurity $[5,6]$. A meta-analysis that reviewed data from Asia, Africa and Latin America found that these risks were highest among nulliparous women under 18 years of age in comparison to women with one or two previous pregnancies between 18 and 35 years of age [7]. In addition to maternal age, associations for risk of adverse pregnancy outcomes have been found with parity for maternal height, maternal education, number of antenatal care visits and for newborn sex $[8,9]$.

Neonates born to multiparous women have been found to have higher BWs and better weight gain during infancy [10]. However, these positive effects have been limited to the second or third pregnancies and are associated with younger maternal age. Women with parity over three and age 35 or older have been found to have higher odds of adverse outcomes in low and middle-income settings [7].

The higher risks that infants of nulliparous women face may be associated with factors related to immaturity of the mother: incomplete growth, small size of the uterus and fetal competition for nutrients [7, 11]. Although the exact mechanisms are not clear, it seems that the first pregnancy "primes" the body for subsequent ones.

In this paper, our aim is to determine the association between parity and BW among women in five research sites of the MNHR. Because of its cohort design, large sample size, multiple sites and the quality of the data (including gestational age dating with first trimester ultrasound, implemented broadly in 2017), the MNHR has the potential to extend the current knowledge of the importance of parity on fetal growth and other offspring outcomes.

\section{Methods}

\section{Study design and population}

Participants were recruited from MNHR sites in the Democratic Republic of Congo (DRC), Guatemala,
Belagavi and Nagpur, India, and Pakistan, between January 2017 and December 2018. All pregnant women living in the defined geographic areas were enrolled in the MNHR during pregnancy and followed from consent until 6 weeks after delivery. Data related to the pregnancy and its outcomes were collected prospectively.

For this analysis, we included women with a first trimester ultrasound examination for determination of gestational age. Exclusions included cases with a maternal death prior to labor/delivery, miscarriage, medical termination of pregnancy, stillbirth, multiple pregnancy, and missing birthweight for gestational age z-score due to missing infant sex, birthweights missing or captured more than 3 days post birth, or gestational age less than 24 or more than 42 weeks. Parity was categorized as: zero (nulliparous), one to three, and four or more previous pregnancies. Maternal height was measured using a stadiometer or scale. Because a large amount of first trimester weight data was missing, neither maternal weight nor body mass index were included in these analyses. Hypertensive disorders were defined as any evidence of hypertensive disease or severe preeclampsia or eclampsia, including elevated blood pressure, proteinuria and/ or seizures. The socioeconomic status index of the household was calculated from 9-items that combine housing conditions and household assets [12]. The index outcomes ranged from 0 (poorest) to 100 (least poor). Gestational age was determined using data from a firsttrimester ultrasound. BW was obtained in grams and later transformed to z-scores adjusted for gestational age using the INTERGROWTH-21st standards [https://inter growth21.tghn.org/]. Neonatal mortality was reported up to 28 days of life.

\section{Data analysis}

Numerical and categorical data were summarized using mean with standard deviation and proportion respectively. Adjusted mean estimates with 95\% confidence interval of both BW and BW z-scores across parity levels were obtained using linear mixed models controlling for the sampling cluster as a random effect. The analysis was adjusted by site, maternal age, height, maternal education, antenatal care, hypertensive disorders, and socioeconomic status. Models were presented by the child's sex and total sample. Separate interaction terms between parity and other variables (maternal age, height, care visits, education, and socioeconomic status) were explored. The associations of parity with mortality and preterm births were assessed via Cochran-Mantel-Haenszel 
tests stratified by cluster. P-value $<0.05$ was considered as significant.

\section{Ethical issues}

The institutional review boards and ethics committees at the participating study sites (Kinshasa School of Public Health, Kinshasa, DRC; INCAP, Guatemala City, Guatemala; KLE University's JN Medical College, Belagavi, India; Lata Medical Research Foundation, Nagpur, India; and Aga Khan University, Karachi, Pakistan), their affiliated US partner institutions (University of North Carolina at Chapel Hill, University of Colorado, Thomas Jefferson University, Boston University, Columbia University, University of Indiana, and the data coordinating center (RTI International) approved the study. Each woman enrolled provided informed consent regarding the use of data related to her pregnancy, including minors 14-17 years of age in countries where married or pregnant minors (or their authorized representatives) are legally permitted to give consent. All research staff in each country responsible for obtaining consent were trained and certified in matters related to human protection and ethical procedures. Names of women and other personally identifiable information were excluded in the analytical database.

\section{Results}

Of the 82,150 deliveries that occurred in participating sites of the MNHR between January 2017 and December 2018, 8630 were excluded due to multiple pregnancy, medical termination of pregnancy, stillbirth. Most exclusions $(n=50,999)$ were due to lack of first trimester ultrasound, resulting in 15,121 (18.4\%) deliveries that met the inclusion criteria for analysis (Fig. 1). Overall, nulliparous women made up $57.8 \%$ of the sample, women with one to three previous pregnancies accounted for $37.7 \%$, and women with four or more previous pregnancies, $4.5 \%$. Site differences were observed in the distribution of parity with $39.7 \%$ of nulliparous women enrolling at the Belagavi site and the DRC and Pakistan sites contributing the most women with parity $\geq 4$ ( $39.8 \%$ and $36.4 \%$ respectively). In the study sample, nulliparous women were younger and shorter, had received more education than parous

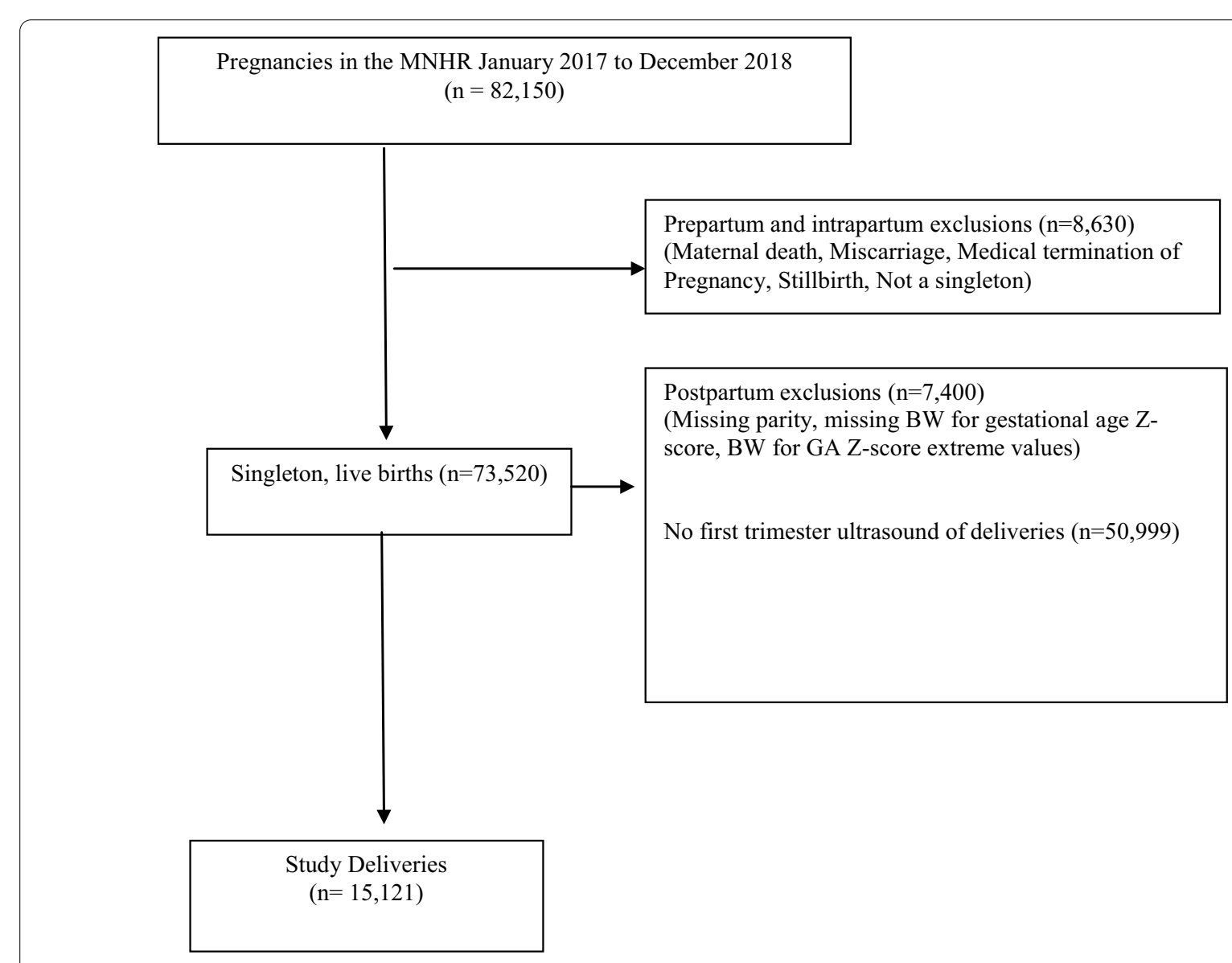

Fig. 1 Enrollment flow diagram 
women combined and had a higher prevalence of hypertensive diseases/severe preeclampsia/eclampsia (p-values <0.01) (Table 1). Due to observed differences in sites regarding the distribution of parity, site was adjusted for in all analyses assessing the association of parity with BW. However, site was no longer significant after adjusting for these maternal characteristics.

Nulliparous women had 1.5 times higher rates of low BW (<2500 g) infants than parous women (Table 2). Infants of nulliparous women had a significantly higher 28-day mortality rate (27.7 per 1000 live births) than women with one to three (17.2 per 1000) and four or more $(20.7$ per 1000) pregnancies $(\mathrm{p}=0.0006)$. There was also a significantly higher proportion of preterm infants in women with four and more previous pregnancies. $15.5 \%$ of infants born to these women were preterm compared to $11.3 \%$ for the nulliparous group and $11.8 \%$ for women with one to three previous pregnancies $(\mathrm{p}=0.0072)$.
In a model controlling for cluster as a random effect and adjusting for site, parity, maternal age, height, education, hypertensive disorders, antenatal care and socioeconomic status, nulliparous also had significantly lower mean BWs (Table 3). Increases in BW were associated with increasing parity up to four or more previous pregnancies overall and for male infants; the largest increases overall and for males (64 $\mathrm{g}$ and $76 \mathrm{~g}$, respectively) occurred between the infants of nulliparous women and women with one previous pregnancy. Female infant birthweight was over $50 \mathrm{~g}$ greater between infants of nulliparous women and women with one previous pregnancy as well as between infants of women with three versus two previous pregnancies.

The adjusted BW for gestational age z-scores (WAZ) by parity, categorized by infant sex, are presented in Fig. 2. The WAZ score of infants of nulliparous women were significantly lower than those of women with one, two or three previous pregnancies in male infants, in

Table 1 Maternal characteristics and outcomes by parity

\begin{tabular}{|c|c|c|c|c|c|}
\hline & \multirow[t]{2}{*}{ Nulliparous } & \multicolumn{2}{|l|}{ Parous } & \multirow[t]{2}{*}{ Total } & \multirow{2}{*}{$\begin{array}{l}\text { Nulliparous } \\
\text { vs. Parous } \\
\text { p-value }\end{array}$} \\
\hline & & 1 to 3 & 4 or more & & \\
\hline Total sample size & 8742 & 5703 & 676 & 15,121 & \\
\hline Study site, N (\%) & & & & & $<0.0001$ \\
\hline $\mathrm{DRC}$ & $974(11.1)$ & $503(8.8)$ & $269(39.8)$ & $1746(11.5)$ & \\
\hline Guatemala & $1344(15.4)$ & $673(11.8)$ & $83(12.3)$ & $2100(13.9)$ & \\
\hline Belagavi, India & $3473(39.7)$ & $3,546(62.2)$ & $77(11.4)$ & $7096(46.9)$ & \\
\hline Nagpur, India & $1748(20.0)$ & $455(8.0)$ & $1(0.1)$ & $2204(14.6)$ & \\
\hline Pakistan & $1203(13.8)$ & $526(9.2)$ & $246(36.4)$ & $1975(13.1)$ & \\
\hline Maternal age, N (\%) & & & & & $<0.0001$ \\
\hline$<20$ & 2965 (33.9) & $145(2.5)$ & $1(0.1)$ & $3111(20.6)$ & \\
\hline $20-35$ & $5753(65.8)$ & $5466(95.8)$ & $560(82.8)$ & $11,779(77.9)$ & \\
\hline$\geq 36$ & $24(0.3)$ & $92(1.6)$ & $115(17.0)$ & $231(1.5)$ & \\
\hline Maternal height, N (\%) (cm) & & & & & 0.0024 \\
\hline$<145$ & $835(9.6)$ & $453(7.9)$ & $37(5.5)$ & $1325(8.8)$ & \\
\hline $145-155$ & $5292(60.5)$ & $3587(62.9)$ & $322(47.6)$ & $9201(60.9)$ & \\
\hline$\geq 156$ & $2614(29.9)$ & $1663(29.2)$ & $317(46.9)$ & $4594(30.4)$ & \\
\hline Maternal education, N (\%) & & & & & $<0.0001$ \\
\hline No formal education & $1308(15.0)$ & $840(14.7)$ & $391(57.8)$ & $2539(16.8)$ & \\
\hline Primary/secondary & $6063(69.4)$ & $4248(74.5)$ & $279(41.3)$ & $10,590(70.0)$ & \\
\hline University & $1370(15.7)$ & $615(10.8)$ & $6(0.9)$ & $1991(13.2)$ & \\
\hline Antenatal care visits, Mean (SD) & $4.9(1.8)$ & $4.7(1.7)$ & $4.2(2.0)$ & $4.8(1.8)$ & $<0.001$ \\
\hline \multicolumn{6}{|l|}{ Socioeconomic status score, N (\%) } \\
\hline$<34$ & $1135(13.9)$ & $582(11.3)$ & $314(50.3)$ & 2031 (14.6) & 0.8085 \\
\hline $34-65$ & $3360(41.1)$ & 2202 (42.8) & 235 (37.7) & 5797 (41.6) & \\
\hline$\geq 66$ & $3677(45.0)$ & 2360 (45.9) & 75 (12.0) & $6112(43.8)$ & \\
\hline $\begin{array}{l}\text { Hypertensive disease/severe preeclamp- } \\
\text { sia/eclampsia, N (\%) }\end{array}$ & $498(5.7)$ & $150(2.6)$ & $19(2.8)$ & 667 (4.4) & $<0.0001$ \\
\hline
\end{tabular}

a p-values for categorical maternal characteristics are based on Cochran-Mantel-Haenszel tests of each characteristic and nulliparous vs. parous stratified by cluster, while $\mathrm{p}$-values for continuous maternal characteristics are based on t-tests comparing the difference in the means of nulliparous vs. parous for each characteristic 
Table 2 Neonatal characteristics by parity

\begin{tabular}{|c|c|c|c|c|c|}
\hline & Nulliparous & Parous & & Total & Nulliparous \\
\hline & & 1 to 3 & 4 or more & & $\begin{array}{l}\text { vs. parous } \\
\text { p-value }\end{array}$ \\
\hline Study population & 8742 & 5703 & 676 & 15,121 & \\
\hline Gender, N (\%) & & & & & 0.0703 \\
\hline Male & $4551(52.1)$ & $2914(51.1)$ & $335(49.6)$ & $7800(51.6)$ & \\
\hline Female & $4191(47.9)$ & $2789(48.9)$ & $341(50.4)$ & $7321(48.4)$ & \\
\hline Gestational age, N (\%) & & & & & 0.0072 \\
\hline Preterm (<37 weeks) & $992(11.3)$ & $674(11.8)$ & $105(15.5)$ & $1771(11.7)$ & \\
\hline Term ( $\geq 37$ weeks) & $7750(88.7)$ & $5029(88.2)$ & $571(84.5)$ & $13,350(88.3)$ & \\
\hline Birth weight categories, N (\%) & & & & & $<0.0001$ \\
\hline$<1500$ & $72(0.8)$ & $40(0.7)$ & $4(0.6)$ & $116(0.8)$ & \\
\hline $1500-2000$ & $470(5.4)$ & $175(3.1)$ & $28(4.1)$ & $673(4.5)$ & \\
\hline $2001-2500$ & $2054(23.5)$ & $922(16.2)$ & $101(14.9)$ & $3077(20.3)$ & \\
\hline$\geq 2501$ & $6146(70.3)$ & $4566(80.1)$ & $543(80.3)$ & $11,255(74.4)$ & \\
\hline Mean (SD) & $2738.7(445.8)$ & $2840.4(427.5)$ & $2907.4(478.6)$ & $2784.6(444.0)$ & $<0.0001$ \\
\hline $\begin{array}{l}\text { Neonatal deaths }<28 \text { days, } \mathrm{N} \\
\text { (Rate } / 1000)\end{array}$ & $242(27.7)$ & $98(17.2)$ & $14(20.7)$ & $354(23.4)$ & 0.0006 \\
\hline
\end{tabular}

${ }^{a}$ p-values for categorical maternal characteristics are based on Cochran-Mantel-Haenszel tests of each characteristic and nulliparous vs. parous stratified by cluster, while $\mathrm{p}$-values for continuous maternal characteristics are based on t-tests comparing the difference in the means of nulliparous vs. parous for each characteristic

Table 3 Adjusted estimated BW $(95 \% \mathrm{Cl})$, in grams, by parity

\begin{tabular}{|c|c|c|c|c|c|c|}
\hline & \multicolumn{2}{|l|}{ Male } & \multicolumn{2}{|c|}{ Female } & \multicolumn{2}{|l|}{ Total } \\
\hline & $\mathbf{N}$ & Mean BW & $\mathbf{N}$ & Mean BW & $\mathbf{N}$ & Mean BW \\
\hline Nulliparous & 4245 & $2676(2636,2717)$ & 3914 & $2587(2546,2628)$ & 8159 & $2634(2604,2663)$ \\
\hline 1 & 1669 & $2752(2706,2798)$ & 1567 & $2643(2596,2690)$ & 3236 & $2698(2664,2732)$ \\
\hline 2 & 684 & $2777(2725,2830)$ & 656 & $2675(2622,2728)$ & 1340 & $2725(2687,2764)$ \\
\hline 3 & 270 & $2803(2738,2867)$ & 288 & $2737(2674,2800)$ & 558 & $2766(2721,2812)$ \\
\hline 4 or more & 302 & $2823(2763,2883)$ & 313 & $2727(2669,2786)$ & 615 & $2774(2731,2817)$ \\
\hline$p$-value & & $<0.0001$ & & $<0.0001$ & & $<0.0001$ \\
\hline
\end{tabular}

Estimated birthweight and p-values overall and by infant sex are from a linear mixed model with BW as the outcome controlling for cluster as a random effect and adjusting for site, parity, maternal age, height, education, hypertensive disorders, antenatal care and socio-economic status

female infants, and overall (based on non-overlapping confidence intervals, results not shown). The largest incremental differences in z-scores were observed between infants of nulliparous women and women with one previous pregnancy overall as well as for male and female infants $(0.36,0.28$, and 0.32 , respectively). Overall, increases in WAZ scores were associated with increasing parity up to three previous pregnancies. There was no interaction of parity with maternal age, height, education antenatal care visits, or socioeconomic status on the association with BW for gestational age z-scores.

\section{Discussion}

In line with previous studies, the nulliparous women in this study of five low and middle-income country sites had lower mean BWs and WAZ scores than women with one, two or three previous pregnancies $[10,13,14]$. We also found the largest incremental differences between zero and one pregnancies. However, we did not find interactions between parity and the characteristics of maternal age, maternal height, antenatal care visits, socioeconomic status, or maternal education with respect to the association with parity (results not shown).

The higher neonatal mortality rates in our study among infants of nulliparous women and the higher proportion of preterm infants in women with four or more pregnancies are also similar to results from previous reports [7]. This is important information for choosing antenatal care in the perinatal period, as it indicates the vulnerability that nulliparous women face, independent of other risk factors. This large, multi-site cohort study strengthens the existing knowledge by including the analysis of other covariates in nulliparous women of low and middleincome settings. 


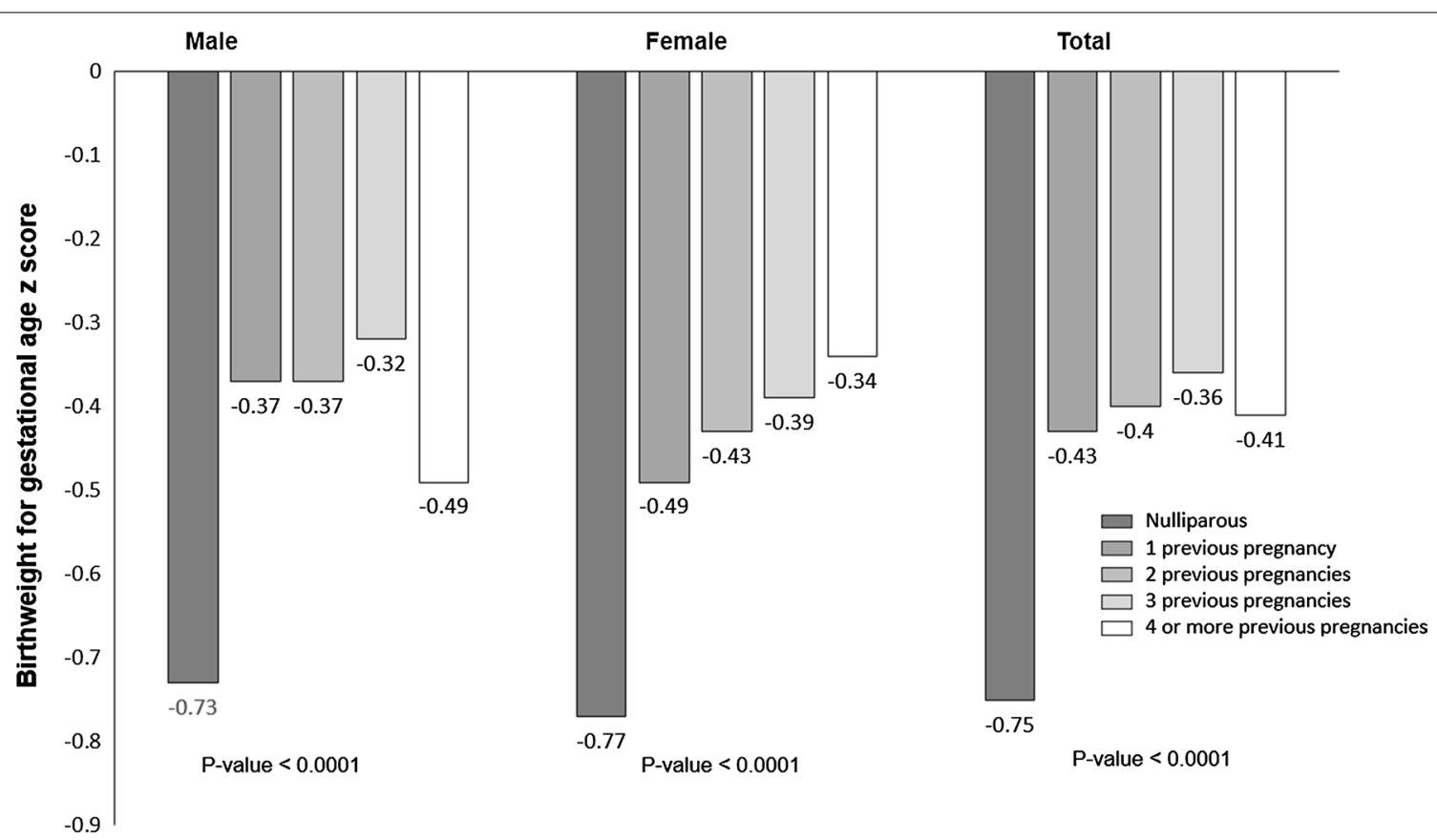

Fig. 2 Adjusted birth weight for gestational age z-scores and parity by infant sex. Estimated BW for gestational age $z$-scores and p-values overall and by infant sex are from a linear mixed model with $z$-score as the outcome controlling for cluster as a random effect and adjusting for site, parity, maternal age, height, education, hypertensive disorders, antenatal care, and socio-economic status

Because of the multiple sites and large number of participants, the MNHR has the potential to extend the current knowledge of the importance of parity on fetal growth and other pregnancy outcomes [5, 7]. This study provides quantitative data on differences in BW, preterm birth, and neonatal mortality by parity for five low-income sites. Additionally, the effect of nulliparity independent from age, which differs from prior studies, adds to the evidence base. These results can inform public health strategies geared both at nulliparous women and those with greater than four prior pregnancies residing in high-risk settings.

The strengths of this study include the ultrasound determination of gestational age that allowed for an accurate estimation of $\mathrm{BW}$ for gestational ageadjusted $\mathrm{z}$ scores and preterm birth. However, the limited availability of first trimester ultrasound reduced our sample size and resulted in inclusion of less than one-fourth of the women participating in the MNHR for this analysis. This may have biased our results in favor or women who enrolled in the MNHR in the first trimester. Strengths of the study included the large sample size, multiple sites on 3 continents, and standard data collection methodologies.

\section{Conclusions}

This analysis confirms that in low and middle-income countries, the infants of nulliparous women have lower BWs and higher neonatal mortality than women with one to four previous pregnancies. The association between parity and birthweight was not affected by maternal age, height, education, antenatal care visits, hypertensive disorders, or socioeconomic status. These results contribute to the evidence base on pregnancy outcomes and may have implications for the targeting of nutritional and reproductive interventions aimed at improving pregnancy outcomes in low and middleincome settings.

\section{Abbreviations}

BW: Birth weight; MNHR: Maternal Newborn Health Registry; DRC: Democratic Republic of Congo; WAZ: Weight for age z-scores; GN: Global Network for Women's and Children's Health Research; NICHD: Eunice Kennedy Shriver National Institute of Child Health and Human Development.

\section{Acknowledgements}

Not applicable.

\section{About this supplement}

This article has been published as part of Reproductive Health, Volume 17 Supplement 3, 2020: Global Network MNH. The full contents of the 
supplement are available at https://reproductive-health-journal.biomedcent ral.com/articles/supplements/volume-17-supplement-3.

\section{Authors' contributions}

ALG, WP, NFK and KMH conceived of the manuscript and wrote the first draft with input from MSH, KSH, TLN, RLG, ABP, PLH, AL, AT, SS, SSG, RJD, JP, MKT, EMM. ALG, ABP, AL, AT, SS, and SSG oversaw study implementation, data collection and quality monitoring. KSH, TLN and EMM performed the statistical analyses. All authors reviewed the final manuscript. All authors read and approved the final manuscript.

\section{Funding}

Publication of this supplement is funded by Grants from Eunice Kennedy Shriver National Institute of Child Health and Human Development NICHD (UG1HD076474) to the participating sites and to RTI International. The study was funded by Grants from the Eunice Kennedy Shriver National Institute of Child Health and Human Development of the US National Institutes of Health.

\section{Availability of data and materials}

Data from the study will be available at the NICHD data repository (N-DASH): https://dash.nichd.nih.gov/.

\section{Ethics approval and consent to participate}

This study was reviewed and approved by all sites' ethics review committees (INCAP, Guatemala; Aga Khan University; KLE Academy of Higher Education and Research's Jawaharlal Nehru Medical College, Belagavi; Lata Medical Research Foundation, Nagpur), and the institutional review boards at each U.S. partner university and the data coordinating center (RTI International). All women provided informed consent for participation in the study, including data collection and the follow-up visits.

\section{Consent for publication}

The article was approved for publication by NICHD through its clearance mechanism

\section{Competing interests}

The authors declare that they have no competing interests.

\section{Author details}

1 Instituto de Nutrición de Centroamérica y Panamá, Guatemala City, Guatemala. ${ }^{2}$ University of Colorado School of Medicine, Denver, CO, USA. ${ }^{3}$ RTI International, Durham, NC, USA. ${ }^{4}$ Department of Obstetrics and Gynecology, Columbia University School of Medicine, New York, NY, USA. ${ }^{5}$ Lata Medical Research Foundation, Nagpur, India. ${ }^{6}$ Boston University School of Public Health, Boston, MA, USA. ${ }^{7}$ Kinshasa School of Public Health, DRC, Kinshasa, Congo. ${ }^{8}$ Aga Khan University, Karachi, Pakistan. ${ }^{9}$ KLE Academy Higher Education and Research J N Medical College Belagavi, Karnataka, India. ${ }^{10}$ Thomas Jefferson University, Philadelphia, USA. ${ }^{11}$ University of North Carolina at Chapel Hill, Chapel Hill, USA. ${ }^{12}$ Eunice Kennedy Shriver National Institute of Child Health and Human Development, Bethesda, MD, USA

Received: 23 October 2020 Accepted: 28 October 2020

Published: 17 December 2020

\section{References}

1. Goudar SS, Carlo WA, Mcclure EM, Pasha O, Patel A, Esamai F, et al. The Maternal and newborn health registry study of the global network for women's and children's health research. Int J Gynaecol Obs. 2012;118(3):190-3. https://doi.org/10.1016/j.ijgo.2012.04.022.

2. Bose CL, Bauserman M, Goldenberg RL, Goudar SS, McClure EM, Pasha $\mathrm{O}$, et al. The Global Network Maternal Newborn Health Registry: a multinational, community-based registry of pregnancy outcomes. Reprod Health. 2015;12(2):S1. https://doi.org/10.1186/1742-4755-12-S2-S1.

3. Hoffman MK, Goudar SS, Kodkany BS, Goco N, Koso-Thomas M, Miodovnik $M$, et al. A description of the methods of the aspirin supplementation for pregnancy indicated risk reduction in nulliparas (ASPIRIN) study. BMC Pregnancy Childbirth. 2017;17(1):135. https://doi.org/10.1186/s1288 4-017-1312-x.

4. Pasha O, Goldenberg RL, McClure EM, Saleem S, Goudar SS, Althabe F, et al. Communities, birth attendants and health facilities: a continuum of emergency maternal and newborn care (the global network's EmONC trial). BMC Pregnancy Childbirth. 2010. https://doi. org/10.1186/1471-2393-10-82.

5. Hinkle SN, Albert PS, Mendola P, Sjaarda LA, Yeung E, Boghossian NS, et al. The association between parity and birthweight in a longitudina Consecutive pregnancy cohort. Paediatr Perinat Epidemiol. 2014;28(2):106-15.

6. Shah PS. Parity and low birth weight and preterm birth: a systematic review and meta-analyses. Acta Obstet Gynecol Scand. 2010;89:862-75. https://doi.org/10.3109/00016349.2010.486827.

7. Kozuki N, Lee AC, Silveira M, Victora CG, Adair L, Humphrey J, et al. The associations of parity and maternal age with small-for-gestational-age, preterm, and neonatal and infant mortality: a meta-analysis. BMC Public Health. 2014;13(Suppl 3):S2. https://doi.org/10.1186/1471-2458-13-s3-s2.

8. Althabe F, Moore JL, Gibbons L, Berrueta M, Goudar SS, Chomba E, et al. Adverse maternal and perinatal outcomes in adolescent pregnancies: The Global Network's Maternal Newborn Health Registry study. Reprod Health. 2015;12(2):S8. https://doi.org/10.1186/1742-4755-12-S2-S8.

9. Griffiths PL, Balakrishna N, Fernandez Rao S, Johnson W. Do socioeconomic inequalities in infant growth in rural India operate through maternal size and birth weight? Ann Hum Biol. 2016;43(2):154-63. https ://doi.org/10.3109/03014460.2015.1134656.

10. Sha T, Gao X, Chen C, Li L, Cheng G, Wu X, et al. Associations of prepregnancy BMl, gestational weight gain and maternal parity with the trajectory of weight in early childhood: a prospective cohort study. Int J Environ Res Public Health. 2019. https://doi.org/10.3390/ijerph16071110.

11. Chen XK, Wen SW, Fleming N, Demissie K, Rhoads GG, Walker M. Teenage pregnancy and adverse birth outcomes: a large population based retrospective cohort study. Int J Epidemiol. 2007;36(2):368-73. https://doi. org/10.1093/ije/dyl284.

12. Reay $\mathrm{H}$, Sears J. A collaborative model for training clinical research staff. Nurs Manag. 2013;20(3):22-7. https://doi.org/10.7748/nm2013.06.20.3.22. e1073.

13. Patel AB, Bann CM, Garces AL, Krebs NF, Lokangaka A, Tshefu A, et al. Development of the Global Network for Women's and Children's Health Research's Socioeconomic Status Index for use in the network's sites in low and lower middle-income countries. BMC Rep Health. https://doi. org/10.1186/s12978-020-01034-2

14. Garces A, Perez W, Figueroa L, et al. Term offspring of nulliparous women have lower weight for age $Z$ scores than multiparous women in Chimaltenango, Guatemala. In: American Society of nutrition 2019 conference.

\section{Publisher's Note}

Springer Nature remains neutral with regard to jurisdictional claims in published maps and institutional affiliations. 